THE WABASH CENTER

JOURNAL oN TEACHING
BOOK REVIEW

\section{The Teacher's Role in the Changing Globalizing World: Resources and Challenges Related to the Professional Work of Teaching}

\author{
Handle Niemi, Auli Toom, Arto Kallioniemi, and Jari Lavonen, editors \\ Leiden, The Netherlands: Brill, 2018 ( $v+154$ pages, ISBN 978-90-04-37257-3, \$54.00)
}

\section{Reviewed By}

Daniel D. Scott

Tyndale University
No one anticipated the incredible change in the teacher's role that would come as a result of the COVID-19 pandemic. Within days, teachers of all age levels were suddenly compelled to adapt their teaching techniques and styles in response to social distancing. For many, this meant providing instruction completely online.

A global group of scholars, presciently, called attention to the need for teachers to adapt to twenty-first century realities, including the need to prepare teachers for cyber learning for themselves and their students. As Mingyuan Gu from Beijing Normal University says, "With the development of new technology, teacher's traditional roles are ... facing . . . more challenges" (109).

In order to meet the challenges of the various educational environments and systems, a variety of solutions are offered. The Finnish educational system calls for high professional autonomy and responsibility; the American higher educationsystem, likewise, requires decentralization and professional autonomy. Educators from Finland and Estonia call attention to the delicate balance between the role of the teacher and the person of the teacher. Scholars from China and Singapore, meanwhile, call for a new role for twenty-first century teachers that goes beyond the Sage, Guide, and Meddler to include Knowledge Broker and Pedagogical Weaver so that teachers might have the "identity and capacity to adaptively employ a blend of different pedagogical roles when necessary" (28). Contributions from scholars in Estonia and Malta draw attention to the need for professional development for in-service teachers. Dutch scholars point to the need for teacher education policies to be reformulated to allow for innovation and reform.

Ee-Ling Low of the National Institute of Education at the Nanyang Technological University shares a story about such rethinking in Singapore. Teachers in Singapore make a pledge upon entry into pre-service education and upon graduation from pre-service. The pledge confirms that there is one central mission of the teacher: to guide students to become good and useful citizens in an ever-changing world. As a result of the massive problems confronting the world, education systems need to adapt. In order to prepare students to solve the world's problems, teachers in Singapore are urged to allow students exposure beyond the walls of the school "via digitally enabled, simulated forms of reality" (138). In so doing, students will be prepared to take on jobs not yet created.

A concluding chapter summarizes the contributions of the other nine and makes the case that teachers are part of educational ecosystems and that they, therefore, "must identify, analyze, and manage educational systems and their subsystems and understand what comprises teachers' roles within the systems" (141). That is, teachers must adapt to their surroundings as they prepare twenty-first century learners to adapt to an ever-changing world. 